\title{
Efficacy and Safety of Methotrexate Plus Leflunomide Versus Methotrexate Plus Hydroxychloroquine Plus Sulphasalazine in Newly Diagnosed Rheumatoid Arthritis- An Observational Study in Outpatient Department of A Tertiary Care Hospital in West Bengal
}

\author{
Amit Kumar Ghosh ${ }^{1}$, Soumya Bhawal ${ }^{2}$, Mausumi De ${ }^{3 *}$ \\ ${ }^{1}$ Associate Professor Department of Pharmacology, R. G Kar Medical College, Kolkata West Bengal, India \\ ${ }^{2}$ Post graduate tranee Department of Pharmacology, R. G. Kar Medical College, and Kolkata, India \\ ${ }^{3}$ Associate Department of Pharmacology, R. G. Kar Medical College, Kolkata, India
}

DOI: $10.36348 /$ SJMPS.2019.v05i12.001

| Received: 25.11.2019 | Accepted: 03.12.2019 | Published: 09.12.2019

*Corresponding author: Mausumi De

\section{Abstract}

Rheumatoid Arthritis is an autoimmune disorder of unknown etiology. There is no one stop therapy that can cure the disease. The goal of therapy in Rheumatoid arthritis is to induce prolonged remission. Disease Modifying Anti rheumatic Drugs (DMARD) are the drug of choice, can be used either in monotherapy or in combinations of DMARDs. Among all of these DMARD's, commonly methotrexate based combined therapy is used to control the disease. Our present study is to evaluate the response of the drug therapy on disease process and compare the efficacy of the two regimens Methotrexate + Lefunamide vs Methotrexate +Sulfasalazine +Hydroxychloroquine using ACR 20 guideline and also to study the adverse event occuring during this study period. It is a prospective observational study carried out in the department of Pharmacology and Rheumatology outpatient department of R.G. Medical College and Hospital, kolkata. Treating physicians prescribed the drugs according to the condition of the patients without any randomization. Patients were divided into two groups, Group A 60 patients who had been prescribed Methotrexate +Leflunomide, 60 patient of another group (Group B) were prescribed Methotrexate+ Sulphasalazine +Hydroxychloroquine. A questionnaire containing 20 questions (HAQ DI) were given to each patient for assessment of Physical Function at baseline and after 6 months to evaluate the response to drug therapy. After completion of therapy data were analysed by proper statistical method and it was found that our study had shown that efficacy of MTX+SSZ+HCQ (group-B) was statistically better improvement than MTX+LEF (group-A) using ACR20 guideline ( $\mathrm{p}=0.031$ ).

Keywords: Rheumatoid arthritis, methotrexate, lefunamide, sulfasalazine, Hydroxychloroquine, Combined

Copyright @ 2019: This is an open-access article distributed under the terms of the Creative Commons Attribution license which permits unrestricted use, distribution, and reproduction in any medium for non-commercial use (NonCommercial, or CC-BY-NC) provided the original author and source are credited.

\section{INTRODUCTION}

Rheumatoid Arthritis is an autoimmune disorder of unknown etiology. The disease chiefly involves the musculoskeletal system, most notably the synovial joints, causing pain and stiffness. It is a progressive disease that leads to destruction of synovial joints causing deformity, followed by limitation of movement of the joints that leads to disability, loss of livelihood, inability to perform daily routine activities and deterioration of quality of life. Rheumatoid Arthritis (RA) occurs globally with a prevalence of $1 \%$ worldwide, commonly effecting females, with male to female ratio being $1: 3$ to $1: 5[1-3]$. In India the prevalence is $0.5-0.8$ percent of general population [4, 5]. Though the exact cause is unknown, it is postulated that it occurs due to complex interaction of genetic factors and environmental factors.
The exact reasons causing RA is unknown, based on different studies researchers had proposed that RA is caused by complex interactions of Environmental factors and the Genetic factors of an individual which leads to activation of immunity against the constituent of the body. Recently infection by certain microorganism is under investigation as a causal factor of RA.

Environmental Factors: Certain antibodies like anti cyclic citrullinated peptide(CCP), Rheumatoid factors are present in the circulation years before signs and symptoms appears, this had led to studies about different environmental factors influencing RA. Smoking appears to be one of the important factors influencing disease. Attributable population risk is 
about $25 \%$ and about $35 \%$ for RA with presence of Rheumatoid Factor or Anti Citrullin Protein Antibody $[6,7]$.

In addition it has been reported that risk of sero-positive RA associated with smoking is to be highest in those who carry HLA-DRB1 shared epitopes. Smoking and other forms of bronchial stress (e.g., exposure to silica) increase the risk of RA among persons with susceptibility HLA-DR4 alleles [8].

Infectious agents (e.g., Epstein-Barr virus, cytomegalovirus, proteus species, and Escherichia coli) and their products (e.g., heat-shock proteins) have long been linked with RA, although underline mechanisms remain elusive, some form of molecular mimicry is postulated $[9,10]$. The formation of immune complexes during infection may trigger the induction of rheumatoid factor, a high-affinity autoantibody against the Fc portion of immunoglobulin, which has long served as a diagnostic marker of RA and is implicated in its pathogenesis.

It is also a fact that females are affected 3-5 times more than male. It is observed that signs and symptoms of RA subside during pregnancy and subsequently flair up after child birth. Researchers claim that use of OCP, proper breast feeding have a protective action against RA [11-16].

Silica dust and mineral oils seems to be associated with RA [17]. Patients suffering from RA are found to be deficient in vitamin $\mathrm{D}$, many researchers believe that deficiency of vitamin $\mathrm{D}$ may be a factor causing RA $[18,19]$.

Genetic Factors: Patients with RA has very strong family history, Hereditability of RA is estimated to be $60 \%$. However concordance of monozygotic twins was found to be $12-15 \%$ in comparison to dizygotic twins which was 2-4\% [20]. Like all autoimmune diseases HLA genes are also involved in RA, the contribution to HLA to RA is about $30-50 \%$. HLADRB1 shared epitope is an important gene in the disease of RA. In RA nonHLA genes are also involved in disease process. PTPN22, PADI4, STAT4, TRAF1$\mathrm{C} 1$, are some of the nonHLA genes involved in RA.

Pathogenesis: Both T cell as well as B cells is involved in RA. The inflammatory infiltrate consist of $\mathrm{T}$ cells, B cells, plasma cells, denritic cell, mast cells and neutrophils. Antigen presenting cells activates $\mathrm{T}$ cells. $\mathrm{T}$ cells form the major portion of infiltrate. Antibodies are produced by B cells leads to formation of immune complex. Various inflammatory mediators are involved in the process like TNF $\alpha$, IL1, IL6, IL17, IL23, Interferon $\mathrm{V}$, nitric oxide and granulocytic macrophage colony stimulating factor are some of them. Matrix Metalloproteinase (MMP) is an important enzyme secreted from the inflammatory cells that plays important role in pathology $[21,22]$.

Recent researches had shown the role of RANK ligand in RA disease process, RANK ligand stimulates osteoclastic activity.

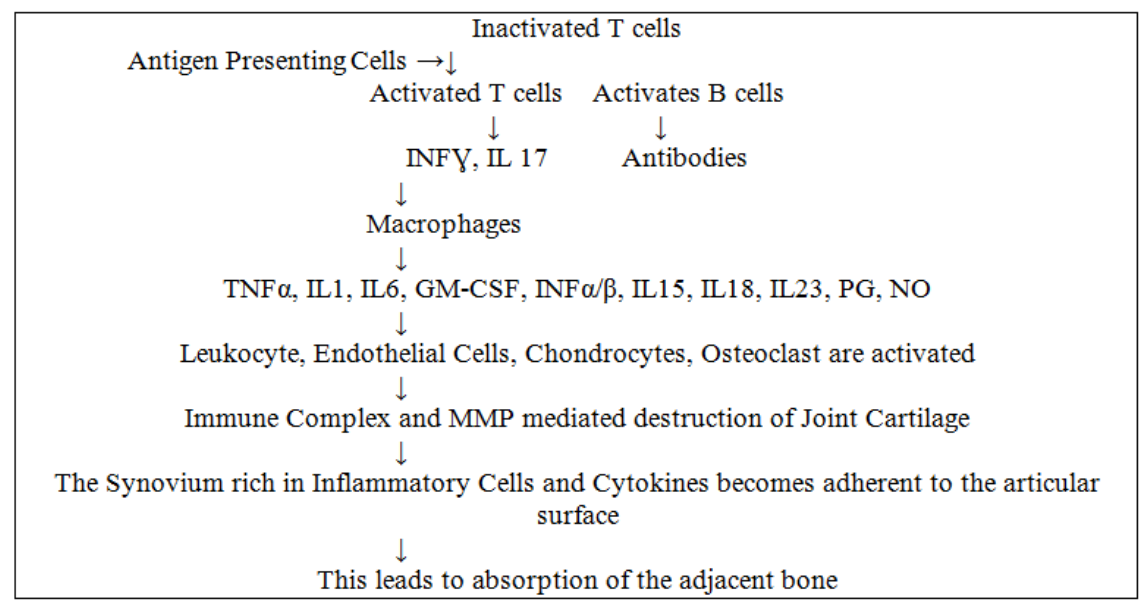

The Pathophysiology of RA involves a complex interaction of three different scientific domains

- A complex genetic predisposition plus environmental stimulus

- A self-perpetuating, self-amplifying synovial immune response

- Finally tissue injury mediated by inflammatory cells, inflammatory effector molecule and degrading enzymes
In individual this process produces a characteristic lesion in synovium as well as hallmark erosion of bone and destruction of cartilage in the synovial joint

Histopathology:- The histopathology of rheumatoid synovium is well established. The synovium, the intestitium and the microvasculature all are involved. Early in the process the synovium lining 
which contains both type A and typeB cells undergo proliferation. The synovium increases in cell number and cell mass. Likewise a diffuse nodular inflammatory cell infiltrate is observed in the interstitium. It contains CD4+, CD8+ lymphocyte, dendritic cells and other antigen presenting cell. In some patient the histological presentation is quite dramatic, it shows the focal aggregate of both $\mathrm{T}$ and $\mathrm{B}$ cells as well as germinal centers like that of lymph node. The synovium of the joint although not malignant behaves like locally invasive tumor. The microvasculature initially reveals endothelial cell activation. As the process matures plasma cell and giant cell appears and vascular supply becomes exuberant. Finally the growing synovium appears as granular tissue as it advances the hyaline cartilage and margin of joint. A local effect of degenerated enzymes and osteoclast produces classical erosions of bone and cartilage margin. The enzyme may also affect the structure that is distant and allied like tendon, ligament and other musculoskeletal structure. Erosions are produce by bone and matrix protein resorbing osteoclast which is induced and activated by cytokines as well as RANK ligand released into the inflammatory milieu [21, 23].

Once the biological inflammation has matured it appears to be regulated, propagated and amplified by inflammatory cells and their chemical mediator most notable being cytokines. The Tcells and antigen presenting cells stimulate macrophages by action of INFY and IL17. Stimulated macrophages secrete pro-17 inflammatory cytokines most notably $\mathrm{TNF} \alpha$ and IL1. IL1 and TNF $\alpha$ or their mRNA had been isolated from serum synovial fluid and tissue of patient with RA. Both these cytokines have broad biological effects including induction of Matrix Metalo Proteinases (MMP) production, as well as inhibiting inhibitors of MMP. In vivo and in vitro studies have documented that combination of TNF $\alpha$ and IL1 injures normal hyaline cartilage. Chondrocytes in particular enter into a catabolic phase on exposure to these cytokines leading to increase in collagenase production and decrease in matrix protein synthesis. TNF $\alpha$ may also induce adhesion molecule like ICAM1, which helps in migration and homing of proinflammatory cells into synovium. The role of TNF $\alpha$ is further established by the efficacy of antiTNF $\alpha$ biolgics like Infliximab, Etanercept, Adalimumab, on the sign, symptoms, structural damage that is charecteristic of RA.
In 1932, International Committee on Rheumatism was formed and it was later renamed as American Rheumatism Association and subsequently, the American College of Rheumatology (ACR). It is an organization of and for the physicians, health professionals and scientists that promote advances in rheumatology through programs of education, research, advocacy and practice support that fosters excellence in care of people with arthritis as also rheumatic and musculoskeletal diseases. A similar organization known as European League against Rheumatism (EULAR) was set up in Europe in 1987.

The goal of therapy in Rheumatoid arthritis is to induce remission, but it is extremely difficult to induce remission, in most cases treating physicians are more concerned with controlling inflammation and pain, thereby slowing the progress of the disease, providing relief to the patient and preventing deformities. There is no one stop therapy that can cure the disease in all the patients. Different DMARD in different combination has been tried and tested on different study population but till now no definite therapy has been able to address the problem. There have been several approaches in combination therapy.

Disease modifying Anti rheumatic Drugs (DMARD) are the drug of choice for Rheumatoid Arthritis. DMARDs can be of recent advanced Biological DMARDs or the conventional DMARDs. They can be used either in monotherapy or in combinations of DMARDs. Among all of these DMARD's, Methotrexate is used world over for treatment of RA. Some authors had described it as an Anchor Drug for treatment of early Rheumatoid Arthritis and is invariably prescribed in a combination or used in monotherapy unless contraindicated or cannot be tolerated [24].

The conventional DMARD like methotrexate are cheap, administered orally and has been described to be very effective in most western journals.

New drugs are discovered using the inflammatory mediators or their receptors as their targets. These drugs are mostly monoclonoidial antibodies that specifically targets different disease process. Many such drugs have been approved and marketed, but they are expensive. 


\begin{tabular}{|l|l|}
\multicolumn{2}{l}{ Table-1: Biologic DMARD and their Target } \\
\hline Abatacept & $\begin{array}{l}\text { Targets CD80 and CD86 on Tcells, blocks Tcell stimulation and blocks inflammatory } \\
\text { cascade, a fusion protein containing cytotoxic T lymphocyte associated antigen4 and FC } \\
\text { portion of IgG1 }\end{array}$ \\
\hline Anakinra & Both membrane bound and soluble IL6 \\
\hline Tocilizumab & receptor antagonist \\
\hline Etanarcept & Blocks soluble TNF $\alpha$ receptors \\
\hline Adalimumab & Human TNF $\alpha$ antibody \\
\hline Infliximab & Chimeric TNF $\alpha$ antibody \\
\hline Rituximab & Chimeric Mab at CD20 of B cells, stops activation of B cells and may induce apoptosis \\
\hline Golimumab & Human anti TNF $\alpha$ antibody \\
\hline Certolizumab-pegol & PEGylated humanized Fab fragment of TNF $\alpha$ antibody \\
\hline
\end{tabular}

Measurement of Functional Status and Quality of Life in Rheumatoid Arthritis: Self-assessment questionnaire like HAQ-DI, HAQ are used to assess the physical ability to carry out day to day activity.

\section{AIMS AND OBJECTIVES}

- To evaluate the response of the drug therapy on disease process and compare the efficacy of the two regimes (MTX+LEF vs MTX+SSZ+HCQ) using ACR 20 guideline

- To study the adverse event occuring during this study period.

\section{MATERIALS AND METHODS \\ Study Design}

It is a prospective observational study carried out in the department of Pharmacology and Rheumatology outpatient department of R.G. Medical College and Hospital. Medications were given to the patients as per the choice of the treating physician according to the condition of the patients without any randomization. Patients who were willing to take part in our study fulfilling the eligibility criteria were included in our study. A written informed consent was taken from each patient.

The patients were divided into two groups. Those who were prescribed Methotrexate $(10 \mathrm{mg}$ oral dose weekly) plus Leflunomide(10-20mg oral once dose daily) were taken in one group (group-A).

While others patients those were prescribed Methotrexate (10mg oral dose weekly) plus Sulphasalazine $(500 \mathrm{mg}$ oral dose twice daily) plus Hydroxychloroquine (400mg oral dose once daily) were taken into another group (group-B)

The patients were followed up in every month for a time period of six months. During each visit clinical parameters like swollen joint count and tender joint count were assessed by the treating physician, Patients were asked to quantify their pain in Visual Analog Scale (VAS), They were also asked to do their own Global Assessment and give a score in Visual Analog Scale (VAS).
A questionnaire containing 20 questions (HAQ DI) were given to each patient for assessment of Physical Function. Few laboratory tests were suggested by treating physician after Rheumatoid Arthritis had been diagnosed. These tests included TB Gold to rule out active tuberculosis. Serological tests for HepatitisB and HepatitisC to exclude their infection. ESR to monitor patient's response to the therapy. Hemoglobin, WBC count, Platelet count, AST and ALT to monitor any adverse drug reaction. During each visit physician also gave a Global assessment. The patient was requested to attend the Rheumatology OPD once every month. The data generated was analyzed in the Department of Pharmacology.

\section{Study Population}

The study population consists of newly diagnosed patients of Rheumatoid Arthritis, attending the Rheumatology OPD in R.G Kar Medical College and Hospital, who had never received any DMARD previously.

\section{Inclusion criteria}

Patient of age $\geq 18$ years of age of either sex attending Rheumatology OPD newly diagnosed with Rheumatoid Arthritis, who had never received DMARD.

\section{Exclusion Criteria}

- Patient below 18 years of age

- Patient having active Tuberculosis

- Patient with positive markers of Hepatitis B and C infections.

- Patients with liver, kidney and neurological disease

- Lactating and pregnant women

- Hemoglobin $<10 \mathrm{gm} / \mathrm{dl}$

- Platelet $<1.5$ lack $/ \mathrm{cmm}$

- $\mathrm{WBC}<4000 / \mathrm{cmm}$

\section{Study Period}

The study was conducted for twelve months starting January 2016 to December 2016, during which study patients were recruited and observed for six month. 


\section{Sample size}

The target sample size was set as 60 patients in each group, a total of 120 patients.

\section{Parameters Evaluated}

- Age, Sex and Body Weight

- Medical History

- Tender and Swollen Joint count

- Patient's Pain using VAS(0-100) score

- Patient's Global Assessment using VAS(0-100) score

- Physician's Global Assessment using VAS(0-100) score

- Health Associated Questionnaire Disability Index ( HAQ DI) for Patient's assessment of Physical Function

- Hemoglobin, Platelet Count, WBC count, ESR, AST, ALT

\section{Drugs Used}

Methotrexate $-10 \mathrm{mg}$ oral dose per week

Leflunamide - 10 to $20 \mathrm{mg}$ oral dose once daily. It is started at $10 \mathrm{mg}$ dose, if response was poor dose is increased.

Sulphasalazine- 500mg oral dose twice daily

Hydroxychloroquine $-400 \mathrm{mg}$ oral dose once daily

D. Concomitant Medication:

Folic Acid - 5mg oral dose once daily

Prednisolone - 5 to $20 \mathrm{mg}$ oral dose daily, started usually at a low dose and then either withdrawn slowly or increased dose depending on the patient's condition.

Ibuprofane - 400mg oral dose twice daily for the first five days, then patients are advised to take the medicine if there is sudden flair up of pain.

Proton Pump Inhibitor - given if patient is having ibuprofane, $40 \mathrm{mg}$ of omeprazole once in the morning taken orally.

Estimation of Acute Phase Reactant (ESR)

ESR was estimated at beginning and end of study.

ACR 20:

ACR 20 criteria is given by American College of Rheumatology to estimate the efficacy of a treatment regimen. It is a composite index consist of eight core parameters these includes

- Swollen Joint Count

- Tender Joint Count

- Patient's Assessment of Pain

- Patient's Global Assessment of Disease Activity

- Physician's Global Assessment of Disease Activity

- Patient's Assessment of Physical Function

- Acute Phase Reactant
- Radiological or other imaging technique ( for study more than one year)

Out of these parameters, for a patient to response to ACR20 criteria there must be $20 \%$ reduction in tender and swollen joint count along with $20 \%$ improvement in any of the three criteria from remaining six parameters. Similarly for ACR 50 and ACR 70 there must be $50 \%$ and $70 \%$ improvement. The ACR criteria is used to measure efficacy in various clinical trials

Measurement of Functional Status and Quality of Life in Rheumatoid Arthritis: Self-assessment questionnaire like HAQ-DI, HAQ are used to assess the physical ability to carry out day to day activity.

To answer these Questions there were four options each having a definite score?

- With no difficulty - score of 0.00

- With some difficulty - score of 0.05

- With much difficulty - score of 0.10

- Cannot do at all - score of 0.15

Total score of the questionnaire ranged from 0 to 3 , where 0 represents minimum disability and 3 represents maximum disability.

\section{Treatment: the goal of treatment is as follows}

- Take away pain.

- Reduce swelling.

- Slow down or stop joint damage.

- Help people feel better.

- Help people stay active.

- Treatment for rheumatoid arthritis may involve:

- Lifestyle changes.

- Medicine.

- Surgery.

- Regular doctor visits.

Treatment can also include patient education, self-management program, support group that helps people learn about treatment, how to talk to doctor, how to exercise and relax, solve problem.

Long-term studies have shown that fewer than $10 \%$ of patients with RA ever go into a prolonged remission. Greater number of tender or swollen joints at disease onset has been correlated with increase disease activity and joint erosion.

\section{RESULTS AND DISCUSSION}

This is a prospective observational study performed in R.G. Medical College in department of Pharmacology and Rheumatology outpatient department which is under the department of Medicine. Permission was taken from Institutional Ethics Committee before conducting the study. 120 newly 
diagnosed DMARD naive cases of Rheumatoid Arthritis were selected. Written consent was obtained from each of the patient. They were divided into two groups.60 patients of one group (Group A) were prescribed Methotrexate (MTX, 10mg oral dose weekly) +Leflunomide(LEF, 10-20mg oral dose once daily).

60 patient of another group(Group B) were prescribed Methotrexate(MTX, 10mg oral dose per week) + Sulphasalazine(SSZ, 500mg oral dose twice daily) +Hydroxychloroquine(HCQ, 400mg oral dose once daily), The allotment were done as per the choice of the treating physician. They were followed up for next six months. Out of the 60 patient in Group A, 52 were followed up till the end, while 8 of them withdrew, out of 60 patients in Group B, 52 patients were followed up till the end, while 8 of them withdrew from study.

Table-2: HAQ DI Questionnaire

\begin{tabular}{|l|l|}
\hline 1 & Dress yourself including shoelace and button \\
\hline 2 & Shampoo your hair \\
\hline 3 & Stand from a straight chair \\
\hline 4 & Get in and out of bed \\
\hline 5 & Cut your own meat \\
\hline 6 & Lift a cup or glass to your mouth \\
\hline 7 & Open a new milk or juice carton \\
\hline 8 & Walk on flat ground outdoor \\
\hline 9 & Climb up five step \\
\hline 10 & Wash and dry your body \\
\hline 11 & Take a tub bath \\
\hline 12 & Get on and off from toilet \\
\hline 13 & Reach and get down an 5 pound object from above your head \\
\hline 14 & Bend down to pick up clothing from the floor \\
\hline 15 & Open car door \\
\hline 16 & Open previously opened jar \\
\hline 17 & Turn faucets on and off \\
\hline 18 & Run errand and shop \\
\hline 19 & Get in and out of car \\
\hline 20 & Do chores such as vaccuming or yard work \\
\hline
\end{tabular}

Table-3: Distribution of patients in different groups

\begin{tabular}{|l|l|l|l|l|l|}
\hline $\begin{array}{l}\text { Drugs } \\
\text { Prescribed }\end{array}$ & $\begin{array}{l}\text { Patient at the } \\
\text { Beginning of } \\
\text { study }\end{array}$ & $\begin{array}{l}\text { Patient at } \\
\text { End of } \\
\text { Study }\end{array}$ & $\begin{array}{l}\text { Withdrawal } \\
\text { due to } \\
\text { SADR }\end{array}$ & $\begin{array}{l}\text { Withdrawal due to } \\
\text { ADR not Compatible } \\
\text { to Patient }\end{array}$ & $\begin{array}{l}\text { Lost and could } \\
\text { not be Follow- } \\
\text { up }\end{array}$ \\
\hline MTX+SSZ+HCQ & 60 & 52 & 1 & 1 & 6 \\
\hline MTX+LEF & 60 & 52 & 1 & 1 & 6 \\
\hline
\end{tabular}

Table-4: Gender Distribution for MTX + SSZ + HCQ

\begin{tabular}{|l|c|l|l|}
\hline Patient's sex & Male-6 & Female-46 & Total-52 \\
\hline percentage & $11.5 \%$ & $88.5 \%$ & $100 \%$ \\
\hline
\end{tabular}

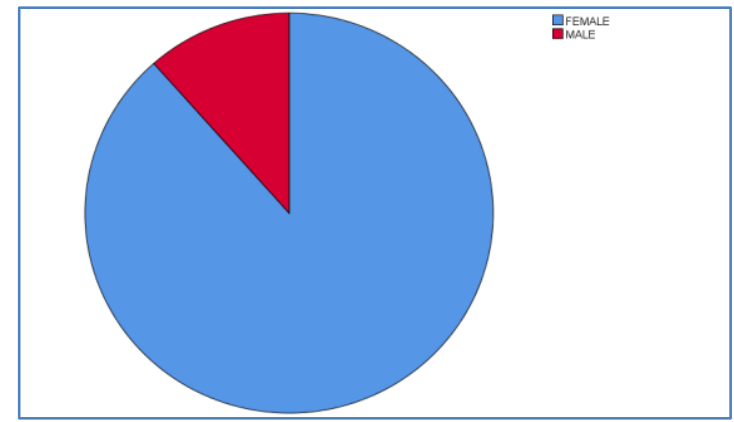

Fig-1: Pie Chart Showing Gender Distribution for MTX+SSZ+HCQ
Table-5: ACR20 Response for MTX+SSZ+HCQ

\begin{tabular}{|l|l|l|}
\hline ACR20 response & Yes & No \\
\hline $\mathrm{N}=52$ & $33(63.46 \%)$ & $19(36.54 \%)$ \\
\hline
\end{tabular}

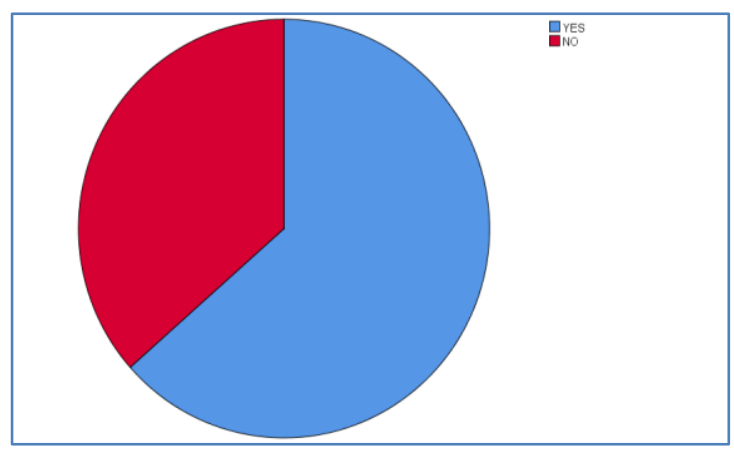

Pie Chart Showing ACR20 Response for MTX+SSZ+HCQ 
Table-6: ACR20 Response for MTX+LEF

\begin{tabular}{|l|l|l|}
\hline ACR20 response & Yes & No \\
\hline $\mathrm{N}=52$ & $22(42.3 \%)$ & $30(57.7 \%)$ \\
\hline
\end{tabular}

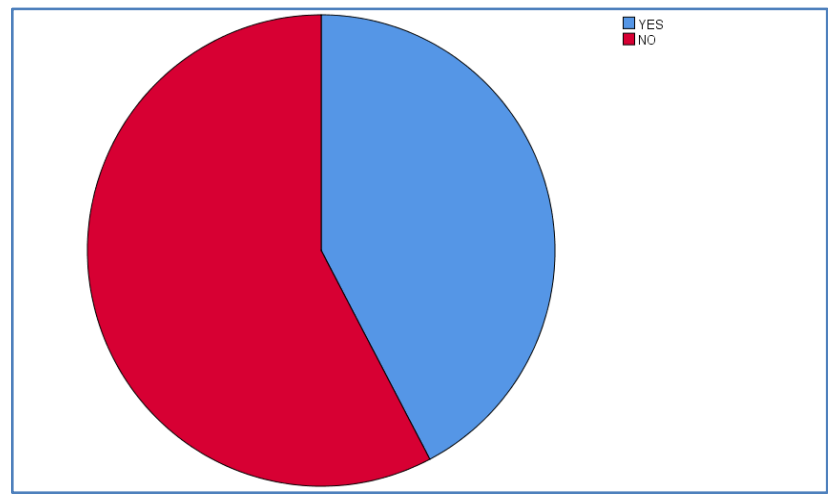

Pie Chart Showing ACR20 Response for MTX+LEF

Table-7: Table Showing Demographic Parameters

\begin{tabular}{|l|l|l|}
\hline Parameters & MTX+SSZ+HCQ & MTX+LEF \\
\hline Age in years (Mean \pm SD) & $38.8077 \pm 8.70438$ & $40.5577 \pm 10.6318$ \\
\hline Gender & $\begin{array}{l}\text { Female- } 46(88.5 \%) \\
\text { Male }-6(11.5 \%)\end{array}$ & $\begin{array}{l}\text { Female }-43(82.7 \%) \\
\text { Male }-9(17.3 \%)\end{array}$ \\
\hline $\begin{array}{l}\text { Mean Duration of Disease in } \\
\text { Months(Mean } \pm \text { SD) }\end{array}$ & $7.2 \pm 2.673$ & $6.333 \pm 2.522$ \\
\hline $\begin{array}{l}\text { Mean Body Weight } \\
(\text { Mean } \pm \text { SD) }\end{array}$ & $58.18 \pm 7.053$ & $60.25 \pm 7.728$ \\
\hline
\end{tabular}

It is evident that majority of the patient in our study was female, in the group of MTX+SSZ+HCQ females constituted $88.5 \%$ while in the group of
MTX+LEF females constituted $82.7 \%$. No statistical significant difference was found for body weight and duration of disease in between two groups.

Table-8: Comparing Reduction of Core Sets of Parameters in Both the Regimes

\begin{tabular}{|l|l|l|l|}
\hline Parameters & MTX+SSZ+HCQ & MTX+LEF & P value \\
\hline Tender Joint Count (0-28) (Mean \pm SD) & $10.3846 \pm 6.2721$ & $7.2307 \pm 4.3187$ & 0.004 \\
\hline Swollen Joint Count (0-28) (Mean \pm SD) & $5.3846 \pm 4.2571$ & $2.16954 \pm 3.4638$ & 0.000 \\
\hline Patient assessment of pain (0-100VAS) (Mean \pm SD) & $55.2884 \pm 26.4095$ & $48.07692 \pm 18.99829$ & 0.113 \\
\hline Patient's & $20.8076 \pm 20.3152$ & $0.02529 .03846 \pm 16.48048$ & 0.025 \\
Global assessment (0-100 VAS) (Mean \pm SD) & 0.025 & & 0.025 \\
\hline Physician's Global assessment (0-100 VAS) (Mean \pm SD) & $24.71154 \pm 15.3205$ & $27.59615 \pm 14.83538$ & 0.332 \\
\hline HAQ DI(0-3) (Mean \pm SD) & $0.8215 \pm 0.4934$ & $0.61538 \pm 0.37319$ & 0.018 \\
\hline ESR in mm/hr(Mean \pm SD) & $15.5 \pm 12.2706$ & $15.19231 \pm 7.36989$ & 0.877 \\
\hline
\end{tabular}

From the above table we find a comparison of reduction in mean values of core parameters in ACR20 guideline. From the table we observe that the group of MTX+SSZ+HCQ shows statistically significant difference than the group of MTX+LEF, in reduction of Tender joint count $(p=0.004)$, Swollen joint count $(\mathrm{p}=0.00)$ and HAQ DI $(\mathrm{p}=0.018)$. No statistical significant difference was seen in case of Pain $(\mathrm{p}=0.113)$, Physician's Global Assessment $(\mathrm{p}=.332)$ and ESR $(p=0.877)$. However a paradox was seen in case of Patient's Global Assessment $(p=0.025)$ where
MTX+LEF group showed statistical significant difference than MTX+SSZ+HCQ group. From this table we find that MTX+SSZ+LEF has significantly reduced clinical signs like Tender joint count and swollen joint count. It has also significantly improved physical function than the other group as measured by HAQ DI scale. However when it comes to patient global assessment, MTX+LEF showed better result as evident from comparison of Patient Global Assessment. We have to keep in mind that comparison might have taken place in two unequal groups. 
Table-9: Comparison of Efficacy of MTX+SSZ+HCQ and MTX+LF Using ACR20 Response

\begin{tabular}{|l|l|l|l|}
\hline ACR20 Response & Yes & No & Total \\
\hline MTX+SSZ+HCQ & $33(63.46 \%)$ & $19(36.54 \%)$ & $52(100 \%)$ \\
\hline MTX+LEF & $22(42.30 \%)$ & $30(57.70 \%)$ & $52(100 \%)$ \\
\hline
\end{tabular}

ACR20 is a categorical variable which leads to binomial response; it can either produce a response to ACR20 criteria or no response to ACR20 criteria. Hence we apply a Chi squaire test. Applying Chi Squaire Test p=0.031. Hence Methotrexate + Sulphasalazine +Hydroxychloroquine produce statisticaly significant better response than Methotrexate+ Leflunomide.

\section{Serious Adverse Reaction}

DRESS Syndrome due to Sulphasalazine: It was one of the life threatning adverse reactions requiring hospitalisation diagnosed by the clinician as DRESS Syndrome due to Sulphasalazine Spontanious Bleeding from Gum with Rashes all over the body: The lady had spontanious bleeding from gum with purpuric nonblanching rashes threwout the body Platelet Count $0.77 \mathrm{lac} / \mathrm{ml}, \mathrm{Hb} 7.9 \mathrm{gm} / \mathrm{dl}$.

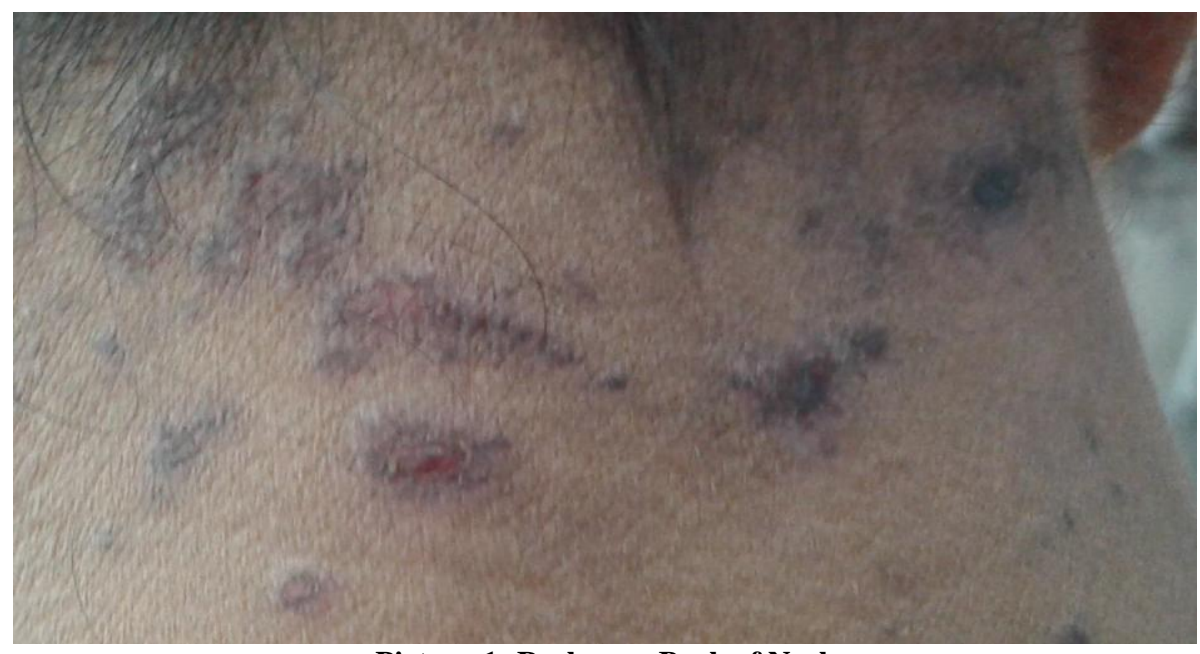

Picture-1: Rashes on Back of Neck

Nausea was the most common adverse event noted, the incidence was higher in $\mathrm{MTX}+\mathrm{SSZ}+\mathrm{HCQ}$ $(20.37 \%)$ than that of MTX+LEF $(7.4 \%)$ but when we applied a Chi Square test no statistically significance was noted (0.051).

In general, barring serious adverse event and one serious adverse in each regime, both the regimes were well tolerated.

\section{DISCUSSION}

Rheumatoid Arthritis is an autoimmune disease of unknown etiology which causes inflammation of synovial joints leading to destruction of cartilage and bones. It leads to deformity of joints, limitation of mobility which leads to disability, deterioration of quality of life, decline in socioeconomic status of an individual and ultimately leads to loss of productivity and economic liability for the society.

Currently there are number of drugs available for treatment of RA, all of which are approved by the different regulatory authorities, however there is no definite solution for entire population. The response to different drug therapy in individual patients is different.
Various medical organizations like EULAR and ACR has been publishing their treatment guideline for the physicians but the treatment remains highly individualized as per the response to the drug. Researchers have suggested that destruction of bones and cartilages can occur early in the disease which is evident from radiological imaging, hence an aggressive therapy using 96 multiple Disease Modifying Anti Rheumatic Drug (DMARD) early in the beginning of the disease is advised [25-27].

We selected 60 patient in each arm, in both the arm 52 patient completed the study, 33(63.46\%) patient on MTX+SSZ+HCQ showed ACR 20 response while in methotrexate+ leflunomide group 22(42.30\%) showed ACR20 response. Using chi-square test, efficacy of methotrexate plus sulphasalazine plus hydroxychloroquinewas found to be significantly greater than methotrexate plus leflunomide $(\mathrm{p}=0.031)$.

On safety profile both the regime had one serious adverse effect. For MTX+SSZ+HCQ a patient was diagnosed as DRESS syndrome due to sulphasalazine and admitted to hospital. The most common adverse event noted in MTX+SSZ+HCQ was nausea $(20.37 \%)$. One of the patient receiving MTX+SSZ+HCQ had hair fall which was unacceptable 
to her and she withdrew. However the overall tolerability of the patients to the regime was good.

In case of methotrexate plus leflunomide one of the patient presented with bleeding gum and nonblanching perpural rash in whole body, her platelet count was 0.77 lack $/ \mathrm{ml}$, and heamoglobin was $7.9 \mathrm{gm} / \mathrm{dl}$. She was advice admission in hospital. One of the patient receiving leflunomide plus methotrexate was found with elevated (>3times the normal upper limit), signifying asymptomatic liver damage. The patient withdrew from the study. The most common adverse reaction in this group suspected to be was nausea $(7.4 \%)$. The overall tolerability of the regime was good.

O' Dell et al.[28] conducted a multicentric two year randomized, double blind, placebo control trial in USA comparing efficacy of $\mathrm{MTX}+\mathrm{SSZ}+\mathrm{HCQ}$ vs $\mathrm{MTX}+\mathrm{SSZ}$ vs MTX+HCQ using ACR20 response criteria. 171 patients were randomized in different groups. Intent-to-treat analysis revealed that patientsreceiving the triple combination responded best, with $78 \%$ achieving an ACR $20 \%$ response at 2 years,compared with $60 \%$ of those treated with MTX andHCQ $(\mathrm{P}=0.05)$ and $49 \%$ of those treated with MTXand SSZ $(\mathrm{P}=0.002)$.

Kremer et al. [29] conducted a 6 months, double-blind, placebo controlled, multicenter study involving 20 centers in North America to compare efficacy of MTX+LEF vs MTX+placebo, using ACR 20 response criteria. 263 patients were randomized in two groups. The overall ACR 20 response rate was $46.2 \%$ of the MTX + LEF group and $19.5 \%$ of the $\mathrm{MTX}+$ placebo group.

Our study result did not corroborate with the previous studies mentioned above. Genetic and Environmental variation could have played a role. Our study being an observational study, no randomization was done. The studies mentioned above are Randomized, double blind study. Baseline data analysis showed that the two groups were not identical in all respect and statistically significant difference existed in the parameters of Patient's Global assessment.

As per the trial carried out by Kremer et al. [29] the common adverse effects due to MTX+LEF were diarrhea $(24.4 \%)$, nausea $(16.2 \%)$, and alopecia $(6.2 \%)$. In recent times however hepatotoxicity had emerged as a major adverse effect and periodic monitoring of liver function is adviced [120]. As per J.R. O'Dell et al.[167], MTX+SSZ+HCQ therapy is well tolerated regime side effects being nausea, weight gain.

Our study had shown that efficacy of $\mathrm{MTX}+\mathrm{SSZ}+\mathrm{HCQ}$ was statistically better than MTX+LEF using ACR20 guideline ( $\mathrm{p}=0.031)$.

\section{CONCLUSION}

Finally we conclude that our study did not corroborate with earlier studies done in the west. Ethnic and environmental variation may have played a role but most importantly, in this study randomization and blinding was not done, which is needed to eliminate bias, and the study was done in very short period. The study was a single center study with limited sample size with poor follow up and doubtful adherence.

\section{REFERANCE}

1. Alamanos, Y., Voulgari, P.V., Drosos, A.A. (2006). Incidence and Prevalence of Rheumatoid arthritis, Based on the 1987 American College of Rheumatology Criteria: A Systematic Review. Semin Arthritis Rheum, 36,182-8

2. Han, C., Robinson, D.W., Hackett, M.V., Paramore, L.C., Fraeman, K.H., Bala, M.V.(2006). Cardiovascular disease and risk factors in patients with rheumatoid arthritis, psoriatic arthritis and ankylosing spondylitis. J Rheumatol, 33, 2167-72.

3. Wolfe, F., Mitchele, D.M., Sibley, J.T. (1994). The mortality of rheumatoid arthritis. Arthritis Rheum, 37, 481-494.

4. Malaviya, A.N., Kapoor, S.K., Singh, R.R., Kumar, A., Pande, I. (1993). Prevalenceof rheumatoid arthritis in the adult Indian population. Rheumatol Int, 13,131-4.

5. Chopra, A., Patil, J., Billempelly, V., Relwani, J., Tandle, H.S. (2001). Prevalenceof rheumatic diseases in a rural population in western India: A WHO-ILAR COPCORD Study. J Assoc Physicians India, 49,240-6.

6. Stolt, P., Bengtsson, C., Nordmark, B. (2003). Quantification of the influence of cigarette smoking on rheumatoid arthritis: results from a population based case-control study, using incident cases. Ann Rheum Dis, 62, 835-841.

7. Kallberg, H., Ding, B., Padyukov, L. (2011). Smoking is a major preventable risk factor for rheumatoid arthritis: estimations of risks after various exposures to cigarette smoke. Ann Rheum Dis, 70, 508-511.

8. Symmons, D.P., Bankhead, C.R., Harrison, B.J. (1997). Blood transfusion, smoking, and obesity as risk factors for the development of rheumatoid arthritis: results from a primary care-based incident case-control study in Norfolk, England. Arthritis Rheum. 40,1955-61

9. Auger, I., Roudier, J. (1997). A function for the QKRAA amino acid motif: mediating binding of DnaJ to DnaK: implications for the association of rheumatoid arthritis with HLA-DR4. J Clin Invest, 99,1818-22

10. Kamphuis, S., Kuis, W. D.E., Jager, W. (2005). Tolerogenic immune responses to novel $\mathrm{T}$-cell epitopes from heat-shock protein 60 in juvenile idiopathic arthritis. Lancet, 366,50-6. 
11. Bhatia, S.S., Majka, D.S., Kittelson, J.M. (2007). Rheumatoid factor seropositivity is inversely associated with oral contraceptive use in women without rheumatoid arthritis. Ann Rheum Dis, 66, 267-269.

12. Doran, M.F., Crowson, C.S., O.Fallon, W.M. (2004). The effect of oral contraceptives and estrogen replacement therapy on the risk of rheumatoid arthritis: a population based study. J Rheumatol, 31, 207-213.

13. Hazes, J.M., Van, Zeben, D. (1991). Oral contraception and its possible protection against rheumatoid arthritis.Ann Rheum Dis, 50,72-74.

14. Brennan, P., Bankhead, C., Silman, A., Symmons, D. (1997). Oral contraceptives and rheumatoid arthritis: results from primary carebased incident case-control study. Semin Arthritis Rheu, 26,817823.

15. Hannaford, P.C., Kay, C.R., Hirsch, S. (1990). Oral contraceptives and rheumatoid arthritis: new data from the Royal College of General Practitioners ${ }^{6}$ oral contraception study. Ann Rheum Dis, 49,744746.

16. Liao, K.P., Alfredsson, L., Karlson, E.W. (2009). Environmental influences on risk for rheumatoid arthritis.CurrOpinRheumatol, 21(3), 279-283.

17. Stolt, P., Kallberg, H., Lundberg, I. (2005). Silica exposure is associated with increased risk of developing rheumatoid arthritis: results from the Swedish EIRAstudy. Ann Rheum Dis, 64, 582-586.

18. Costenbader, K.H., Feskanich, D., Holmes, M. (2008). Vitamin D intake and risks of systemic lupus erythematosus and rheumatoid arthritis in women. Ann Rheum Dis, 67, 530-535.

19. Merlino, L.A., Curtis, J., Mikuls, T.R. (2004). Vitamin D intake is inversely associated with rheumatoid arthritis: results from the Iowa Women's Health Study. Arthritis Rheum, 50, 7277.

20. MacGregor, A.J., Snieder, H., Rigby, A.S., Koskenvuo, M., Kaprio, J., Aho, K., Silman, A.J. (2000). Characterizing the quantitative genetic contribution to rheumatoid arthritis using data from twins. Arthritis Rheum, 43, 30-37.
21. Mc. Innes, I.B., Schett, G. (2011). The pathogenesis of rheumatoid arthritis. N Engl J Med $365,2205-19$

22. Weissmann, G. (2004). Pathogenesis of rheumatoid arthritis. J Clin Rheumatol.10(suppl),S26-S31

23. Nadkarni, S., Mauri, C., Ehrenstein, M.R. (2007). Anti-TNF-alpha therapy induces a distinct regulatory $\mathrm{T}$ cell population in patients with rheumatoid arthritis via TGF-beta. J. Exp Med, 204, 33-9.

24. Pincus, T., Yazici, Y., Sokka,T.,Aletaha, D., Smolen, J.S.(2003).Methotrexate as the "anchor drug" for the treatment of early rheumatoid arthritis. ClinExpRheumatol, 21 (Suppl. 31), S179S185.

25. Breedveld, F.C., Kalden, J.R. (2004). Appropriate and effective management of rheumatoid arthritis Ann Rheum Dis, 63,627-633.

26. Nell,V.P.K., Machold,K.P.,Eberl, G. Stamm, T.A.(2004). UffmannM,SmolenJM.Benefit of very early referral and very early therapywith diseasemodifying anti-rheumatic drugs in patients with early rheumatoid arthritis. Rheumatology, 43,906914

27. Van Jaarsveld, C.H.M., Jacobs, J.W.G., Vander, Veen, M.J., Blaauw, A.A.M., Kruize, A.A. (2000). Aggressive treatment in early rheumatoid arthritis: a randomised controlled trial. Ann Rheum Dis, $59,468-477$

28. O`Dell, J.R., Leff, R., Paulsen, G., Haire, C. (2002). Treatment of Rheumatoid Arthritis With Methotrexate andHydroxychloroquine, Methotrexate and Sulfasalazine, or a Combination of the Three Medications. Arthritis \& rheumatism, $46,1164-1170$

29. Kremer, J.M., Genovese, M.C., Cannon, G.W., Caldwell, J.R., Cush, J.J. (2002). Concomitant leflunomide therapy in patients with active rheumatoid arthritis despite stable doses of methotrexate. A randomized, double-blind, placebo-controlled trial. Ann Intern Med, 137(9),726-33. 